\title{
Antropologia a kultura fizyczna
}

\author{
Zbigniew Drozdowski
}

\begin{abstract}
ANTHROPOLOGY AND PHYSICAL CULTURE. According to the accepted definition of physical culture, the article discusses its relations with anthropology and particularly with anthropology of sports.
\end{abstract}

Problematyka kultury fizycznej należy w ostatnich dziesiątkach lat do najbardziej dynamicznie rozwijających się zarówno pod względem ilościowym, jak też jakościowym. Zintensyfikowanie różnych form jej oddzialywania na coraz liczniejsze ludzkie zespoly nadalo tej formie dzialania szczególne spoleczne znaczenie. Obok dążenia do rozszerzania różnych środków ksztaltującego oddzialywania, pojawiły się również: potrzeba kontroli efektów tego dzialania, wsparcia różnych form kultury fizycznej gruntowną wiedzą o wlaściwościach funkcjonalnych ludzkiego organizmu, a także ludzkich zespolów - zarówno w zakresie ich biologicznych, jak też spolecznych charakterystyk. Prowadzilo to nieuchronnie do pojawienia się różnych form ksztalcenia specjalistów kultury fizycznej - ukoronowanych akademickimi studiami w zakresie tej domeny ludzkiego dzialania. Wraz z pojawieniem się studiów

Zakład Antropologii Sportu AWF

ul. Marchlewskiego 27/39, 61-871 Poznań w zakresie kultury fizycznej, co w Polsce mialo miejsce w 1918 r. na Uniwersytecie w Poznaniu, w ich programie znalazla miejsce także antropologia. Trzeba $w$ tym miejscu podkreślić, że jej różne elementy byly już wcześniej przekazywane adeptom nauczania rozlicznych form ćwiczeń fizycznych, a także byly podejmowane w pracach badawczych. Wedlug M. GoDYCKIEGo [1961] metoda antropologii, mianowicie antropometria zostala wprowadzona do nauczania wychowania fizycznego przez Demeny'ego, przy czym miała ona służyć do kontroli efektów uprawianych ćwiczeń fizycznych, szczególnie wywolanych nimi somatycznych zmian.

Proces wtapiania problematyki antropologicznej w teoretyczne podstawy kultury fizycznej, a także badawcze inspiracje plynące od niej do antropologii stanowily przedmiot prac przedstawianych przez przedstawicieli nauk antropologicznych. Ten fakt zwalnia nas od szczególowego omawiania tej problematyki. Zainteresowanym pragniemy zwrócić uwagę, że 
kolejne etapy prac przedstawiane byly w licznych opracowaniach [DrozDowsKI 1971, 1973, 1980a, 1983, 1985a, 1985b; GoDYCKI 1959, 1961; Milicerowa 1969 , 1970; StojanowsKi 1929].

Przy ogólnej refleksji dotyczącej rozwoju dyscypliny należy zwrócić uwagę także na jej miejsce wśród nauk tworzących podstawy kultury fizycznej, szczególnie ze względu na inspiracje mogące mieć istotne znaczenie w dalszym rozwoju antropologii nadchodzących lat. Stąd też w naszych dalszych rozważaniach podejmujemy próbę odpowiedzi na następujące pytania:

1) jakie są cele i zadania kultury fizycznej we wspólczesnym spoleczeństwie oraz związane $z$ nimi glówne obszary dzialania $\mathrm{i}$ badawcze problemy,

2) jaki jest dotychczasowy wklad antropologii w ich realizację, w tworzenie teoretycznych podstaw kultury fizycznej,

3) jakie zadania plyną dla antropologa ze wspóldziałania w obszarze kultury fizycznej.

Odpowiadając na pierwsze $z$ postawionych pytań należy podkreślić pewną kontrowersyjność określania pojęcia "kultura fizyczna", co jest - między innymi - wynikiem jej dynamicznego rozwoju, wczesnego etapu kształtowania, kiedy wiele kwestii znajduje się dopiero in statu nascendi. Stąd też dla uproszczenia dalszych rozważań przyjmujemy, za naszym wcześniejszym opracowaniem [DrozDowskI 1980], że przez pojęcie kultura fizyczna rozumiemy zespól biospolecznych i organizacyjnych oddzialywań zmierzających do wykorzystania różnych form aktywności ruchowej dla uzyskiwania wyni$\mathrm{ku}$ sportowego, usprawnienia ruchowego czy określonej reakcji żywego organizmu w procesie odnowy biologicznych sil. Jej zadania I Kongres Naukowy Kultury Fizycznej i Sportu sprowadzil do następu- jących [Uchwala ... 1981]: 1. Eliminowanie środkami kultury fizycznej i sportu ujemnych skutków ograniczania aktywności ruchowej czlowieka oraz jego jednostronnej pracy (poczynania te winny prowadzić do rozwijania sprawności fizycznej i podtrzymywania jej $w$ inwolucyjnej fazie $\dot{z} y c i a$ czlowieka). 2. Usprawnienie i wspóludzial w procesie przywracania spoleczeństwu osób poszkodowanych $\mathrm{w}$ czasie pracy $\mathrm{i}$ poza nią (główne zadanie rehabilitacji). 3. Przyspieszenie regeneracji sil biologicznych, odnowa produkcyjnych i twórczych zdolności ludzkich w związku ze znaczną intensyfikacją życia, zwiększeniem obciążenia organizmu ludzkiego wysiłkiem wynikającym $\mathrm{z}$ udziału w procesach produkcji (glówne zadanie rekreacji ruchowej). 4. Ksztaltowanie za pośrednictwem popularnych, dostępnych i masowych widowisk sportowych wzorców indywidualnej aktywności fizycznej, integracji spoleczeństwa i środowisk lokalnych. Wykorzystywanie sportu wyczynowego jako środka wychowania oraz jako swoistego laboratorium badawczego, w którym śledzić można reakcję ludzkiego organizmu w warunkach skrajnych obciążeń.

Jest więc kultura fizyczna zespolem bodźców, które ksztaltują biologiczną wartość ludzkiej populacji, usuwają ujemne skutki naszego stylu życia i pracy, a także przeciwdziałają im, przyczyniają się także do przyspieszenia procesu regeneracji sil oraz rehabilitacji. Swoje zadania realizuje poprzez: 1) wychowanie fizyczne powszechne wszystkich warstw i grup spolecznych, 2) rehabilitację ruchową wspóluczestniczącą w przywracaniu spoleczeństwu w pelni sprawnych jego czlonków, 3) rekreację ruchową i turystykę - przyczyniające się do przyspieszenia procesu odnowy sił produkcyjnych i twórczych zdolności czlowieka, 4) sport - będący $z$ jednej strony 
widowiskiem, a z drugiej sprawdzającym zachowanie czlowieka stawianego w sytuacji skrajnych obciążeń, różne metody $i$ środki ksztaltujące oddzialywanie na ludzki organizm. Wspomniany już I Kongres Naukowy Kultury Fizycznej i Sportu wśród glównych problemów badawczych kultury fizycznej wymienia następujące: a) określenie aktualnego stanu wydolności fizycznej społeczeństwa polskiego, śledzenie zachodzących w niej zmian, a szczególnie skutków spadku aktywności ruchowej spoleczeństwa; b) prowadzenie badań biospolecznych przeslanek doboru i selekcji osobników do różnych form wysilku fizycznego, zarówno w aspekcie przydatności sportowej, jak zawodowej; c) ustalenie teoretycznych podstaw sterowania rozwojem formy sportowej, wydolności ludzkiego organizmu, przebiegiem treningu i walki sportowej oraz procesu odnowy biologicznej organizmu; d) zintensyfikowanie badań nad kulturą fizyczną i sportem jako zjawiskiem spolecznym. W realizacji przytoczonych zadań badawczych istotną rolę spelnia antropologia; niektóre $z$ nich od dawna stanowią przedmiot zainteresowania jej przedstawicieli, a uzyskiwane wyniki wzbogacają wiedzę o czlowieku i ludzkiej populacji w aspektach wlaściwych antropologii.

Przechodząc do odpowiedzi na drugie z postawionych pytań, mianowicie jaki jest dotychczasowy wklad tej dyscypliny do realizacji badawczych zadań kultury fizycznej oraz jej teoretycznych podstaw, należy podkreślić, że pierwszy program zastosowań antropologicznych w wychowaniu fizycznym zostal sprecyzowany przez K. Stojanowskiego $[1927,1929]$ w następujących zadaniach: 1) wyodrębnienie i opis typów sprawności fizycznej, 2) wyodrębnienie i opis typów konstytucjonalnych, 3) rasowe i konstytucjonalne zróżnicowanie sprawności fizycznej. Później zadania antropologii w odniesieniu do kultury fizycznej byly jeszcze niejednokrotnie formułowane. Najpelniejszy wykaz znalazly one w dokonanej przez Komitet Antropologii PAN ocenie nauk antropologicznych w swietle realizacji przez nie uchwal II Kongresu Nauki Polskiej: "W latach najbliższych przed antropologia sportową będą stawały następujące zadania; 1) badanie stanu rozwoju fizycznego i motorycznego populacji polskiej, $\mathrm{z}$ uwzględnieniem zmian zachodzących w badanych charakterystykach pod wplywem przemian środowiska w szerokim tego slowa znaczeniu, w tym także spolecznego, 2) badanie morfofunkcjonalnych uwarunkowań powodzenia w sporcie, w różnych dziedzinach pracy zawodowej oraz ustalanie odpowiednich przeslanek dla poradnictwa sportowego i zawodowego, 3) badanie (we wspóldzialaniu $z$ innymi dyscyplinami) zmian morfofunkcjonalnych zachodzących w organizmie ludzkim pod wplywem wlaściwego współczesnemu czlowiekowi trybu i stylu życia oraz wskazywanie (we wspóldziałaniu ze specjalistami wychowania fizycznego) odpowiednich środków eliminujących skutki ujemne lub zapobiegających im ...". Do zadań tych wlączono również "... badania chronobiologiczne, ze szczególnym uwzględnieniem zaburzeń wywolywanych w naturalnej biorytmice organizmu ludzkiego przez różnorakie modyfikatory biotyczne, abiotyczne i spoleczne ..." [Nauki antropologiczne ... 1979].

Glówne kierunki prac antropologicznych realizowanych $w$ obszarze kultury fizycznej, za naszym wcześniejszym opracowaniem, możemy sprowadzić do następujących [DrozDowski 1983].

A. Opierając się na klasycznej antropometrii adaptowano i opracowywano różne metody i techniki badawcze, szczególnie 
techniki pomiaru motoryczności człowieka dla calego obszaru kultury fizycznej. Wdrożono metody statystyczne do procesów badawczych.

B. Rozszerzono badania ontogenetycznej zmienności ludzkiego organizmu z cech somatycznych na funkcjonalne, doprowadzając do ustalenia sposobów prognozowania wymiarów, proporcji i budowy osobnika na różnych etapach jego ontogenetycznej zmienności.

C. Rozwinięto, we wspóldziałaniu z innymi dyscyplinami, badania różnych aspektów motoryczności czlowieka. Wynikiem tych prac jest stworzenie mierników sprawności fizycznej, prześledzenie ontogenetycznej zmienności cech motorycznych, sprawności fizycznej ujmowanej w różnych aspektach, jak też ich różnorodnych uwarunkowań.

D. Podjęto badania morfofunkcjonalnych uwarunkowań i skutków zwiększonej aktywności fizycznej, znajdujące wyraz w przedstawionych charakterystykach zróżnicowania somatycznego i motorycznego różnych zespolów sportowych. Prowadzilo to do ujęcia teoretycznych przeslanek selekcji i doboru kandydatów do różnych form wysilku fizycznego - tak związanego z wychowaniem fizycznym i sportem, jak też z aktywnoscią zawodowa. Rozszerza to zainteresowania antropologii, a także szeroko rozumianej kultury fizycznej, wiążąc je $z$ ergonomią.

E. W pewnej mierze z ogólnych antropologicznych idei płyną rozwijane w uczelniach wychowania fizycznego badania antropomorfologii części miękkich, szczególnie ukladu mięśniowego.

F. Rozwinięto badania genetycznych uwarunkowań motoryczności czlowieka, prowadzone w różnych aspektach - tak przez ciągle badania bliźniąt, jak też skojarzenia różnych struktur motorycznych $z$ innymi formami zróżnicowania (immunologicznego, dermatoglificznego, cheiliologicznego itp.).

G. Podjęto i rozwinięto badania chronobiologiczne, doprowadzając do poznania i uogólnienia biorytmicznej natury różnych wlaściwości ludzkiego organizmu.

Za tymże opracowaniem glówne wyniki prac prowadzonych $w$ przedstawionych zakresach można sprowadzić do następujących:

A. Wnosząc do wychowania fizycznego antropometrię przyczynia się do rozbudowy wlasnych metod badawczych kultury fizycznej, szczególnie technik pomiarowych motoryczności czlowieka, przekształcając ją z kategorii opisowej w obiektywnie uchwytną wlaściwość ludzkiego organizmu.

B. Rozszerzenie koncepcji typologii antropologicznej na badania typologii somatycznych, motorycznych, funkcjonalnych itp. przyczynilo się do ukierunkowania prac na ujęcie biotypu ludzkiego organizmu, a związanie antropologii $\mathrm{z}$ naukami o kulturze fizycznej pozwala spodziewać się wielce obiecujących wyników.

C. Zbadano wplyw różnych form aktywności fizycznej na rosnący organizm, opisując rolę ćwiczeń fizycznych jako jednego z ważniejszych stymulatorów procesu rozwoju.

D. Opisano charakterystyki somatyczne przedstawicieli większości dyscyplin sportowych, przedstawiając je dla zespolów osobników będących na różnych etapach sportowej kariery. Zbadano także morfologiczne uwarunkowania poziomu wykształcenia różnych cech motorycznych, form sprawności fizycznej czy wyników sportowych. Stworzono tą drogą możliwości prognozowania wyników sportowych. Poszukiwania te legly u podstaw procesów doboru i selekcji realizowa- 
nych w toku uprawiania różnych form zmienionej aktywności fizycznej.

E. Podjęte prace przyczynily się do poznania morfofunkcjonalnych skutków stylu i trybu życia wspólczesnego człowieka, zarówno dodatnich, jak też ujemnych efektów dzialania różnych trendów związanych $\mathrm{z}$ procesami hominizacji, stwarzając przeslanki obiektywizacji przeciwdzialania im, bądź też eliminowania czy łagodzenia ich ujemnych skutków.

Wreszcie nasuwa się pytanie, jakie zadania stają przed antropologią w nadchodzących latach, przy jej wspóldzialaniu z teorią i praktyką kultury fizycznej, w tym również - jakie inspiracje i pola badawcze zyskuje ona dla siebie, dla rozszerzenia i wzbogacenia wlasnej problematyki. W generalnym ksztalcie glówne zadania badawcze antropologii stosowanej $w$ kulturze fizycznej wynikają - w pewnej mierze są nawet tożsame - $z$ przytoczonych ogólnych badawczych problemów stawianych tej domenie ludzkiej dzialalności. $\mathbf{Z}$ pewnym uproszczeniem i w odpowiedniej adaptacji można je sprowadzić do następujących.

1) Rozwijanie i doskonalenie technik badawczych, a szczególnie wdrażanie w naukach o kulturze fizycznej różnych metod badania morfologii ludzkiego ciala i przyswajanie sobie technik badawczych motoryczności czlowieka.

2) Kontynuowanie badań ontogenetycznej zmienności motoryczności czlowieka, ze szczególnym uwzględnieniem produkcyjnego i poprodukcyjnego okresu jego życia.

3) Dalsze badania wplywu zmienionej (zarówno zwiększonej, jak też obniżonej) aktywności ruchowej czlowieka na procesy wzrastania, a także budowę ludzkiego organizmu.

4) Morfologiczne uwarunkowania aktywności ruchowej czlowieka, zarówno przejawiającej się w sporcie i wychowaniu fizycznym, jak też w czynnościach zawodowych.

5) Genetyczne uwarunkowania aktywności fizycznej czlowieka.

6) Chronobiologiczne przesłanki morfofunkcjonalnych zmian ludzkiego organizmu w czasie i pod wplywem różnych form aktywności fizycznej czlowieka (tak związanej bezpośrednio z ćwiczeniami, jak również aktywnością zawodową).

7) Biologiczne przeslanki doboru i selekcji do różnych form aktywności fizycznej (zarówno sportowej, jak też zawodowej) czlowieka.

Przekonani jesteśmy, że bogactwo rozwijającego się życia wspólczesnego spoleczeństwa rozszerzy także przytoczone zadania. Natomiast $w$ świetle naszych rozważań możemy przyjąc, że w antropologii zarysowal się jej wyspecjalizowany dzial - antropologia sportowa. Zajmuje się ona badaniem morfofunkcjonalnych uwarunkowań fizycznej aktywności czlowieka, zmian morfofunkcjonalnych (również biorytmicznego charakteru tego procesu) zachodzących w ludzkim organizmie w czasie i pod wplywem wykonywania (uprawiania) różnych form aktywności fizycznej, o różnym stopniu intensywności, a występujących zarówno w czasie ćwiczeń fizycznych i sportowego treningu, jak też czynności zawodowych; zmiany te prowadzą do uksztaltowania określonego typu sportowego czy zawodowego, będącego biologiczną odpowiedzią organizmu na stosowane bodźce ruchowe, a także stwarzającego korzystne przeslanki ich rozwoju.

Zamykając nasze rozważania dotyczące problematyki antropologicznej w kulturze fizycznej pragniemy podkreślić, że rozwijala się ona bardzo dynamicznie, szczególnie w tych ośrodkach akademickich, w 
których istnialy uczelnie wychowania fizycznego, lecz byla także podejmowana poza nimi, jeżeli istniało antropologiczne środowisko. Zyskaliśmy bogaty zasób informacji dotyczących biologicznej zmienności ludzkiego organizmu, które weszly na stale do ogólnej antropologicznej problematyki. Możemy przyjąć, że antropologia stala się ważną skladową wśród nauk podstawowych dla kultury fizycznej, przyczyniających się istotnie do rozwoju jej teoretycznych podstaw. $Z$ drugiej strony sama uzyskala inspirację do wlasnego rozwoju oraz wdzięczne pole naukowych dociekań. Dalszy rozwój antropologii sportowej w ścislym wspóldzialaniu z kulturą fizyczną może naszym zdaniem stanowić ważny element składowy ogólnego postępu nauk antropologicznych.

Wlaśnie na przykładzie wspóldziałania z naukami o kulturze fizycznej najpelniej przejawia się dzisiejsze rozumienie antropologii - nauki badającej czlowieka jako biologiczne podloże spolecznych zjawisk, a także biologiczne skutki tych zjawisk, przejawiające się $w$ jego organizmie oraz $w$ ludzkiej populacji.

\section{Piśmiennictwo}

DROZDOWSKI Z., 1971, Tendencje rozwojowe antropologii stosowanej do wychowania fizycznego $i$ sportu w poznariskiej WSWF, [w:] Rozwoj $i$ dorobek antropologii polskiej w 25-leciu PRL, Poznań.

DROZDOWSKI Z., 1973, slan i perspektywy rozwojowe nauk antropologicznych, [w:] Mat. z II Kongresu Nauki
Pol., sekcja XIII Nauk Biol., Warszawa.

DROZDOWSKI Z., 1980a, Kultura fizyczna i jej teoretyezne podstawy w ksztahowaniu wspblczesnego spoleczeristwa, Monogr. AWF w Poznaniu, 194, 11.

DROZDOWSKI Z., 1980b, Próba okreflenia tendencji rozwoju dyscyplin badajqcych przyrodnicze aspekty kultury fizycznej, Monogr. AWF w Poznaniu, 143, 25.

DROZDOWSKIZ., 1983, Aniropologia polska -jejwkiad do teoriiipraktyki kultury fizycznej, Wych. Fiz. i Sport, 3,3.

DROZDOWSKI Z., 1985a, Antropologia sportowa - cele $i$ zadania $w$ swielle aktualnych tendencji rozwoju kullury fizycznej, Roczniki Nauk. AWF w Poznaniu, 32, 27.

DROZDOWSKI Z., 1985b, Wktad Polskiej Szkohy Antropologicznej w rozwój nauk o kulturze fizycznej, [w:] Teoria i empiria, J. Piontek, A. Malinowski red., Poznań.

GODYCKI M., 1959, Antropologia w wychowaniu fizycznym. 40 lat od Katedry WF UP do WSWF w Poznaniu, Poznax́.

GODYCKI M., 1961, Les succès d'anthropologie polonaise dans le domaine de l'éducation physique, Roczniki Nauk. WSWF w Poznaniu, 2, 65.

MILICEROWA H., 1969, Problemy antropologii w wychowaniu fizycznym i sporcie, Wych. Fiz. i Sport, 3, 3.

MILICEROWA H., 1970, Zastosowania badaf antropologicznych w sporcie, Mat. Sesji Nauk. 25-lecia kultury fizycznej w PRL, 3, 34

Nauki antropologiczne w Swietle uchwat II Kongnesu Nauki Polskiej - stan realizacji, 1979, Raport Komitetu Antropologii PAN (maszynopis), Warszawa.

STOJANOWSKI K,, 1927, Stan i perspektywy badań antropologicznych nad Wielkopolskq, Wych. Fiz., 5, 153.

STOJANOWSKI K., 1929, Niekıóre wyniki antropologiczne prac Laboratorium Antropometrii Stosowanej Studium Wychowania Fizycznego Uniwersytetu Poznaniskiego, Wych. Fiz., 12, 345.

Uchwala I Kongresu Naukowego Kullury Fizycznej i Sportu Kultura fizyczna w słuzbie socjalistycznego polskiego społeczeristwa, I Kongres Naukowy Kultury Fizycznej i Sportu, Poznań 21-24 listopada 1979. Materiały i dokumenty, s. 663, Warszawa.

Referat wygloszony na Konferencji Antropologicznej w Blażejewku, we wrześniu 1985 r.

\section{S u m m a r y}

The interrelation between physical culture and anthropological problems has been shown against the background of the general tasks of physical culture. It was assumed that the physical culture is a set of stimuli which form the biological value of human population, remove the negative results of the style of our life and work, and also counteract them and contribute to the acceleration of the regeneration process of human biological forces and creative abilities. In the realization of the tasks of physical culture, anthropology is cooperating and particularly its specialistic division: sports anthropology. It deals with the investigation of morphological conditionings of human physical activity, morphological changes (also the biorythmical character of this process) taking place in human organism in time and under the influence of the performance of different forms of physical activity having both the character of physical exercises or sports training as well as professional work. 